\title{
Ética y calidad en los servicios de sangre
}

María del Carmen García Crispieri ${ }^{1}$

Resumen: El creciente nexo entre ética-ciencia-tecnología-calidad-sociedad, sobre todo en las cuatro últimas décadas, ha tenido gran implicancia en medicina transfusional. En el presente trabajo se analiza la relación de los aspectos éticos, bioéticos y de calidad entre tales instancias, y su aplicación en el campo de la medicina transfusional, como una consecuencia necesaria de los principios que influyen en la vida física, psicológica y espiritual de las personas.

Palabras clave: ciencia, sociedad, calidad, bioética, donación y transfusión de sangre segura

\section{Ethics and quality in blood services}

Abstract: The increasing link among ethics-science-technology-quality-society, especially in the last four decades, has had great implications in transfusion medicine. In present study, relations among ethics, bioethics and quality aspects and their application in the field of transfusion medicine are analyzed, as a necessary consequence of principles that influence physical, psychological and spiritual lives of persons.

Key words: science, society, quality, bioethics, secure blood donation and transfusion

\section{Ética e qualidade nos serviços de sangue}

Resumo: $\mathrm{O}$ crescente nexo entre ética-ciência-tecnologia-qualidade-sociedade, sobretudo nas quatro últimas décadas, tem tido grande implicação na medicina transfusional. No presente trabalho se analisa a relaçẫo dos aspectos éticos, bioéticos e de qualidade entre tais instâncias e sua aplicação no campo da medicina transfusional, como uma consequência necessária dos princípios que influem na vida física, psicológica e espiritual das pessoas.

Palavras-chave: ciência, sociedade, qualidade, bioética, doação e transfusão de sangue segura

\footnotetext{
${ }^{1}$ Médico, Hematólogo-Hemoterapueta. Coordinadora General del Programa Nacional de Sangre, Ministerio de Salud y Deportes, La Paz, Bolivia

Correspondencia: jloebiocal@hotmail.com
} 


\section{Introducción}

La medicina transfusional se relaciona con las ciencias sociales por ser una disciplina científica que se ocupa de aspectos del comportamiento y actividades humanas, y en la que se examinan tanto las manifestaciones materiales como las inmateriales de sociedades e individuos. La característica principal es que los seres humanos poseen habilidades cognitivas que crean una conciencia y representaciones mentales abstractas, las cuales, en general, influyen en su conducta, creando reglas complejas de interacción entre individuos.

$\mathrm{Al}$ otorgar las ciencias sociales un mayor énfasis al método científico u otros métodos rigurosos de análisis, la mayoría de ellas —en el estado actual de conocimientos - no puede establecer leyes de alcance universal, por lo que muchas veces el objetivo es simplemente interpretar los hechos humanos, aunque abundan en los últimos tiempos los intentos genuinamente científicos de formular predicciones cualitativas. Con frecuencia, las interpretaciones de la actividad humana se basan en la comprensión de las intenciones subjetivas de las personas, ante la producción, difusión y aplicación de herramientas que permitan transmitir el conocimiento, pero carecen de sentido si no se aplica el principio del humanismo, que constituye el fundamento de toda actividad científica en la que interacciona la vida, el bienestar, la salud, la cultura, la libertad y el progreso del hombre. La bioética vincula la ética con la medicina, humanizándola, y ayudando a los pacientes a tomar conciencia de sus derechos.

El objetivo del presente trabajo es analizar el nexo indisoluble entre calidad, aspectos éticos y sociales de la ciencia, y la aplicación de todo ello en el campo de la medicina transfusional.

\section{Reflexiones actuales}

La nueva situación, en la cual el individuo es la principal autoridad decisoria sobre cuestiones relacionadas con valores, preferencias, estilos de vida y metas personales, exige concentrarse en "los cuatro principios que configuran el "mantra de Georgetown": autonomía, beneficencia, no maleficencia y justicia(1).
En los últimos 25 años la autonomía ha tomado cuerpo, colocándose a la par de la beneficencia como principio fundamental de la ética médica. Resultado de ello es que la relación entre el personal de la salud con el donante o paciente es ahora más franca y abierta, y se respeta más su dignidad y su autodeterminación a través del consentimiento informado.

Desarrollar un programa de calidad en medicina transfusional requiere de una política y de una planificación rigurosa, en la que los dos niveles de atención — los bancos de sangre como entidades productoras de hemocomponentes seguros y los servicios responsables de las transfusiones de sangre seguras - cuenten con ambientes específcamente diseñados y una organización estructural y funcional claramente normada, además de profesionales y técnicos debidamente capacitados y competitivos para el desarrollo de sus actividades. Ello asegura un tratamiento que garantiza calidad y competencia del servicio, a través del cumplimiento de estándares obligatorios o de procedimientos operacionales, sin que ello implique un gran despliegue de acciones o inversiones.

Por calidad debe entenderse un proceso multifacético, cuyas dimensiones más importantes son: acceso al servicio, competencia técnica, eficiencia, eficacia, buenas relaciones interpersonales, continuidad, disponibilidad y seguridad. En su conjunto, ellas permiten analizar problemas, medir estándares y, sobre todo, satisfacer las expectativas razonables del usuario y del personal. No obstante, sin un comportamiento basado en principios éticos este proceso pierde esencia, por lo que todo accionar debe ser guiado por un sentimiento humano de servicio y no bajo presiones de cualquier orden.

La necesidad de una moral profesional adquiere mayor relevancia en profesiones biomédicas, en las cuales toda actividad tiene como sujeto al ser humano, así como la producción de determinadas sustancias que repercuten directamente sobre su salud y bienestar. Ello requiere prácticas sociales con sentido humanístico y moral, habiéndose convertido en un tema de creciente interés público en la medida en que se acentúa el cariz 
tecnológico y político de la "medicina a medida", ampliando sus capacidades para "intervenir" sobre la vida de las personas(2).

La reflexión bioética proporciona un contexto filosófico y moral para resolver los retos de la medicina transfusional actual y su proyección, en los que la extracción de sangre humana, mediante donaciones voluntarias altruistas, o el uso de los hemocomponentes de orden biológico, utilizados mediante transfusiones, se inscriben como principios públicos en un contexto legal y ético en el que están involucrados los bancos de sangre, los servicios de transfusión, el personal que trabaja en estas instituciones, los donantes, el médico, los pacientes y la sociedad en general.

El gran desarrollo de los últimos años, con los avances obtenidos en biología molecular e informática, llevan a los trabajadores de la salud a capacitarse y actualizarse, y a estar atentos ante las implicaciones negativas que pudiesen tener las aplicaciones equivocadas en perjuicio del individuo, la colectividad y el medio ambiente(3).

\section{Calidad del servicio}

En todo el mundo viene procurándose activamente la aplicación del concepto de "calidad en la atención de salud", lo cual reviste particular importancia en los servicios de sangre, donde el producto que se ofrece y la prestación que se brinda deben ser plenamente seguros, no sólo para acrecentar la confianza de la sociedad en estos servicios, sino para suprimir los peligros de dañar "transmitiendo enfermedades" a través de la transfusión de sangre.

Si bien la Federación Internacional de Sociedades de la Cruz Roja y de la Media Luna Roja proporcionan principios y directrices para aplicar los procedimientos de calidad en los programas de sangre, y suministran o ayudan a suministrar no menos de un tercio de la provisión mundial de sangre segura, la política de calidad queda como responsabilidad específica de dichos programas(47)2. Entonces, los servicios de sangre han debido ${ }^{2}$ Política de Suministros de Calidad en los Servicios de Sangre. La presente política fue aprobada por la Asamblea General de la Federación Internacional de Sociedades de la Cruz Roja y de la Media Luna Roja en su duodécimo período de sesiones, celebrado en octubre de 1999. desarrollar una serie de políticas nacionales para cubrir los dos tercios de las demandas insatisfechas, asumiendo las responsabilidades derivadas.

En la región de las Américas, gracias a los esfuerzos desplegados por la Organización Panamericana de la Salud (OPS/OMS), los servicios de sangre muestran actualmente grandes adelantos. Todos los gobiernos se preocupan por desarrollar servicios de sangre debidamente estructurados, bajo estándares claramente definidos para una gestión de calidad, con donaciones voluntarias altruistas, tamizaje laboratorial del $100 \%$ a toda unidad extraída, almacenaje de disponibilidad suficiente, sostenibilidad y mantenimiento de costos operativos aceptables $(8,9)$.

La actual disponibilidad de información estructurada acerca de los servicios de todos los países y territorios del continente americano, que proporciona la OPS/OMS sin excepción alguna, permite conocer las realidades específicas de cada país, comparar resultados e identificar las deficiencias que aún queda por subsanar(10).

Una de las prioridades es resolver la suficiencia de sangre y su disponibilidad para tratar a los pacientes oportunamente y con el mayor grado de seguridad y calidad posibles. Para garantizarlo, la clave es la promoción de la donación voluntaria, repetida y no remunerada de sangre, en la cual la población juega un rol importante en el marco de la responsabilidad civil y la solidaridad, teniendo en cuenta que la sangre donada debe valorarse como un recurso público.

El nexo calidad-ética-responsabilidad exige la aplicación del proceso de hemovigilancia o seguimiento de pacientes para determinar reacciones adversas a las transfusiones, así como la eventualidad de posibles transmisiones de enfermedades infecciosas, convertidas éstas en ejes estratégicos en las diferentes políticas nacionales y, por tanto, en los sistemas nacionales de sangre.

Una gestión de calidad implica contar con infraestructura debidamente diseñada que brinde confort y bienestar; una organización estructural y funcional normada que traduzca los requisitos mínimos necesarios para cada una de las etapas 
de los procesos y procedimientos, y prestatarios con una conducta ética capaces de brindar información veraz, oportuna y suficiente, acompañada de un trato cálido y solidario que satisfaga a los donantes y usuarios, respetando sus individualidades sociales, culturales, religiosas e incluso económicas(11-17).

La salud y el bienestar del donante y del receptor, a lo largo de toda la cadena transfusional, deberán estar garantizados en el más alto nivel posible de seguridad y calidad. Se observará tanto el Código de Ética para la donación y la transfusión de sangre de la Sociedad Internacional de Transfusión de Sangre(18), adoptado por la Conferencia Internacional de la Cruz Roja y de la Media Luna
Roja en 1981, que desde hace muchos años cuenta con el apoyo de la Organización Mundial de la Salud (OMS), así como las normativas nacionales, respetando la interculturalidad de los pueblos.

Finalmente, son las sociedades nacionales, en un plano de control social, quienes deben cerciorarse de que todos los programas de sangre observen estrictamente los criterios, detalles y aplicación de la política de calidad, así como la conducta ética de todos los miembros del personal y de los voluntarios que intervengan en los programas de sangre. Asimismo, se debe controlar que los gobernantes cumplan y los gobernados estén adecuadamente informados de la política misma.

\section{Referencias}

1. Lolas F, Martin DK, Quezada A. Prioridades en salud y salud intercultural. Estudios de bioética social $\mathrm{N}^{\circ}$ 1. Santiago de Chile: Programa de Bioética OPS/OMS y Cieb, Universidad de Chile; 2007.

2. Piña de Rosario M. Ética, moral y axiología. Disponible en http://momografias.com Consultado en enero/2004.

3. Riffaud MJF. Ética y comunicación. Diplomado internacional de medicina transfusional Concepción: Universidad de San Sebastián.

4. Federación Internacional de Sociedades de la Cruz Roja y Media Luna Roja. Transf Int 1998; 73: $1-10$

5. Grífols J, Argelagues EV, Urcelay SU, Grífols JR, García A. Gestión en el banco de sangre. Barcelona: Pecalo; 1998

6. Chassaigne M. La calidad en la transfusión sanguinea. Diplomado internacional de medicina transfusional. Concepción: Universidad de San Sebastián.

7. González Lastre Y, Trujillo Rexach ME, Beltrán Hernández J. Análisis de la calidad total en los servicios en el Banco de Sangre de Marianao. Universo Diagnóstico 2000; 1(1): 1-41.

8. Número especial sobre los servicios de sangre en la región. Revista Panamericana de Salud Pública 2003; OP 153.

9. WHO. El uso clinico de la sangre: manual de bolsillo. Código WHO 36; 2002.

10. Cruz JR. Los servicios de sangre en la región de las Américas. Revista Panamericana de Salud Pública 2003; 13(2-3).

11. Guia de control de implementación de los "Estándares de Trabajo para Bancos de Sangre". OPS/OMS; febrero de 2002.

12. Luna Orosco J, et al. Serie de documentos técnicos normativos de mejoramiento de la calidad para establecimientos de salud. Publicaciones Nos 57 a 66. La Paz: Ministerio de Salud y Deportes, Área de Calidad en Salud y Auditoría Médica; 2008.

13. Luna Orosco J. Bases para la organización y funcionamiento del Proyecto Nacional de calidad en Salud (PRONACS). La Paz: Ministerio de Salud y Deportes, Área de Calidad en Salud y Auditoría Médica; 2008

14. Estándares de Trabajo para Servicios de Sangre. La Paz: Ministerio de Salud y Deportes, Programa Nacional de Sangre, OPS; 2004. 
15. García MC, et al. Serie de documentos técnicos normativos de mejoramiento de la calidad y conducta ética para servicios de sangre. Publicaciones $\mathrm{N}^{\text {os }} 1$ a 6. La Paz: Ministerio de Salud y Deportes, Programa Nacional de Sangre; 2010.

16. Ledesma L, Franco E. Implantación del Sistema de Gestión de la calidad ISO 9001:2000 en centros y servicios de transfusión. La Paz: Grupo Acción Médica S.A.; 2007.

17. Normas bolivianas de sistemas de gestión de la calidad ISO 9001:2008. IBNORCA/IRAM. 2008.

18. SITS. Código de ética para la donación y transfusión de sangre. Transf Int 1991; 57: 6-8.

Recibido: 27 de julio de 2010

Aceptado: 13 de septiembre de 2010 